\title{
Real-time polymerase chain reaction for microbiological diagnosis of parapneumonic effusions in Canadian children
}

\author{
Jeffrey M Pernica MD ${ }^{1}$, loana Moldovan², Francis Chan $\mathrm{PhD}^{2}$, Robert Slinger $\mathrm{MD}^{2}$
}

\begin{abstract}
JM Pernica, I Moldovan, F Chan, R Slinger. Real-time polymerase chain reaction for microbiological diagnosis of parapneumonic effusions in Canadian children. Can J Infect Dis Med Microbiol 2014;25(3):151-154.
\end{abstract}

BACKGROUND: Community-acquired pneumonia (CAP) complicated by parapneumonic effusion/empyema is an infectious syndrome commonly encountered by physicians caring for children in Canada. OBJECTIVE: To investigate the incremental benefit of novel molecular testing for the microbiological diagnosis of pediatric CAP complicated by parapneumonic effusion/empyema in Canada.

METHODS: A convenience sample of pleural fluid from 56 children who had been admitted to hospital in Ontario with CAP complicated by parapneumonic effusion between 2009 and 2011 was examined. Multiple uniplex real-time polymerase chain reaction (PCR) testing was performed on these pleural fluids and compared with traditional culture-based testing of blood and pleural fluid samples.

RESULTS: Molecular methods detected a pathogen in $82 \%$ of cases, whereas traditional cultures of blood and pleural fluids detected a pathogen in only $25 \%$. The majority of parapneumonic effusions were associated with pneumococcal infection; Streptococcus pneumoniae was detected in $62 \%$ of the samples using molecular methods but in only $14 \%$ of samples using culture-based methods. Streptococcus pyogenes, detected in $16 \%$ of samples using PCR, was the second most common pathogen found. No patients were found to have empyema caused by Staphylococcus aureus.

DISCUSSION: The results showed that multiple uniplex real-time PCR performed substantially better than traditional culture methods for microbiological diagnosis of CAP complicated by effusion/ empyema. S pneumoniae and S pyogenes were found to be responsible for the majority of infections. The approach detected pathogens in a similar proportion of pleural fluid samples as previously reported nested PCR assays; furthermore, the real-time closed-well approach also minimized the risk of nonspecificity due to cross-contamination relative to nested PCR.

CONCLUSIONS: Real-time PCR for the detection of bacterial DNA in pleural fluids has the potential to better define the microbiological cause of pediatric CAP. This approach could help clinicians provide targeted antimicrobial therapy.

Key Words: Empyema; Pleural effusion; Pneumonia; Polymerase chain reaction

\footnotetext{
C
} ommunity-acquired pneumonia (CAP) commonly occurs in children. Pediatric hospitalization rates for CAP in the Western world are one to four per 1000 per year, with pneumonia accounting for up to $20 \%$ of all pediatric admissions in some settings (1). Streptococcus
La réaction en chaîne de la polymérase en temps réel pour le diagnostic microbiologique des épanchements parapneumoniques chez les enfants canadiens

HISTORIQUE : La pneumonie d'origine non nosocomiale (PONN) compliquée par un épanchement parapneumonique ou un empyème est un syndrome infectieux qu'observent souvent les médecins qui soignent des enfants au Canada.

OBJECTIF : Examiner les avantages incrémentiels de nouveaux tests moléculaires pour poser un diagnostic microbiologique de PONN pédiatrique compliquée par un épanchement parapneumonique ou un empyème au Canada.

MÉTHODOLOGIE : Les chercheurs ont examiné un échantillon de commodité de liquide pleural prélevé chez 56 enfants hospitalisés en Ontario à cause d'une PONN compliquée par un épanchement parapneumonique entre 2009 et 2011. Ils ont effectué de multiples tests de réaction en chaîne de la polymérase (PCR) uniplexe en temps réel sur ce liquide pleural et les ont comparés aux examens classiques des cultures de sang et de liquide pleural.

RÉSULTATS : Les méthodes moléculaires ont permis de déceler un pathogène dans $82 \%$ des cas, tandis que les cultures classiques de sang et de liquide pleural n'ont permis d'en déceler que dans $25 \%$ des cas. La majorité des épanchements parapneumoniques s'associait à une infection pneumococcique. En effet, les chercheurs ont décelé un Streptococcus pneumoniae dans $62 \%$ des échantillons au moyen des méthodes moléculaires, mais seulement dans $14 \%$ des échantillons au moyen des méthodes de culture. Le Streptococcus pyogenes, décelé dans $16 \%$ des échantillons par PCR, était le deuxième pathogène en importance à avoir été décelé. Aucun patient n'avait d'empyème causé par le Staphylococcus aureus.

EXPOSÉ : Les résultats ont démontré que de multiples tests de PCR uniplexe en temps réel donnaient des résultats beaucoup plus précis que les cultures classiques pour poser un diagnostic microbiologique de PONN compliquée par un épanchement ou un empyème. Le $S$ pneumoniae et le $S$ pyogenes étaient responsables de la majorité des infections. Cette méthode permet de déceler des pathogène dans une proportion similaire d'échantillons de liquide pleural que les PCR nichées déclarées antérieurement. De plus, la technique en temps réel par système fermé réduisait le risque de non-spécificité attribuable à la contamination croisée observée en cas de PCR nichée.

CONCLUSIONS : La PRC en temps réel pour déceler l'ADN bactérien dans le liquide pleural définit peut-être mieux la cause microbiologique de la PONN pédiatrique. Cette approche pourrait aider les cliniciens à proposer un traitement antimicrobien ciblé.

pneumoniae is the most common bacterial cause of pediatric CAP $(2,3)$; the introduction of the conjugate pneumococcal vaccine in North America led to a substantial decrease in pneumonia incidence (4). Curiously, subsequent to this, rates of CAP complicated by

${ }^{1}$ Department of Pediatrics, Division of Infectious Disease, McMaster University, Hamilton; ${ }^{2}$ Department of Pathology and Laboratory Medicine,

Division of Microbiology, University of Ottawa, Ottawa, Ontario

Correspondence: Dr Jeffrey Pernica, McMaster Children's Hospital, 1280 Main Street West, Room 3A-30, Hamilton, Ontario L9H 4K6.

Telephone 905-521-2100 ext 76947, fax 905-308-7548, e-mail pernica@mcmaster.ca 
parapneumonic effusion were observed to increase in Canada and other countries (5-7).

The optimization of the antimicrobial management of CAP with parapneumonic effusion is important because children with this type of infection are often severely ill, requiring admission to hospital, and many require radiological or operative intervention. Choosing empirical antimicrobial therapy is difficult because there are numerous pyogenic bacteria in addition to $S$ pneumoniae that cause complicated CAP. These include Staphylococcus aureus (both methicillin sensitive and methicillin resistant), group A streptococcus (Stretococcus pyogenes), Streptococcus anginosus group organisms, Haemophilus influenzae, anaerobes and others (8-11). Specific (ie, targeted) antibiotic therapy is not possible in the majority of cases because blood and pleural fluid cultures have been shown to be positive in only $17 \%$ to $35 \%$ of children (8-13). The low sensitivity of pleural fluid cultures in particular may be due to the fact that antibiotics are often started before pleural fluid specimens are obtained. A recent prospective study that enrolled children with complicated pneumonia presenting to the largest children's hospital in Canada (11) obtained a microbiological diagnosis using culture-based techniques in only 22 of 88 participants. The vast majority of these children were treated with multiple parenteral antimicrobials and more than one-half received vancomycin, yet only a single case of methicillin-resistant $S$ aureus empyema was documented.

Molecular techniques may be uniquely well suited to the microbiological diagnosis of complicated CAP because, in contrast to traditional culture-based methods, detection is not predicated on the growth of viable bacteria. However, molecular methods have their own limitations: false-positive results may result from inadequately controlled background contamination (14) or because of very low bacterial concentrations that are not clinically significant but detectable by the assay (15), among other reasons.

The purpose of the present study was to determine whether the microbiological diagnosis of CAP with parapneumonic effusion in children could be improved using nonculture-dependent molecular testing of pleural fluids for bacterial pathogens. Although similar studies have described the results of molecular testing to define bacterial etiology of pediatric parapneumonic effusion in American and European populations $(8,9,12,16-19)$, there is very little in the published literature documenting the Canadian experience with these techniques.

\section{METHODS}

\section{Study population}

Children with pneumonia and parapneumonic effusion often receive thoracentesis and/or thoracostomy tube placement for both diagnostic and therapeutic purposes as part of routine care at the Children's Hospital of Eastern Ontario (CHEO, Ottawa, Ontario) and McMaster Children's Hospital (MCH, Hamilton, Ontario). A convenience sample of pleural fluids from children with a diagnosis of complicated pneumonia/ empyema/parapneumonic effusion were collected at CHEO $(n=47)$ between January 2009 and March 2011, and at MCH (n=9) between December 2010 and March 2011. The infectious disease service at both hospitals had been involved with all study participants. Any pleural fluid from a patient without a diagnosis of complicated CAP (eg, from neonates with fetal hydrops) was not eligible for inclusion. All children with complicated $\mathrm{CAP}$ at both $\mathrm{CHEO}$ and $\mathrm{MCH}$ during the study period were treated empirically with broad-spectrum intravenous antimicrobials; antibacterials were continued if cultures were negative and rationalized if cultures were positive. Because the present study was retrospective in design, molecular testing results were not available to the treating clinicians. The present study was approved by the Research Ethics Boards of both CHEO and McMaster University (Hamilton, Ontario).

\section{Traditional culture-based sample processing}

As part of routine care, all pleural fluids were processed using standard microbiological methods. Aliquots were plated on sheep blood, chocolate and MacConkey agar under aerobic conditions at $37^{\circ} \mathrm{C}$ and monitored daily for five days. An aliquot was inoculated into thioglycollate broth and aliquots were plated on anaerobic agar media and kept for five days under strict anaerobic conditions; these were also checked daily after being left initially for $48 \mathrm{~h}$. Bacteria were identified using standard laboratory methods. First, Gram stain, colony morphology and growth characteristics on culture media were examined. Based on these results, additional tests were performed. For example, optochin and bile solubility were performed for S pneumoniae identification; latex agglutination for group A antigen and bacitracin disk testing were performed for $S$ pyogenes; and for streptococcal species other than $S$ pyogenes and S pneumoniae, an API 20 Strep test (bioMérieux, USA) was performed.

The majority of patients had blood drawn at the study sites and cultures processed using the BacT/Alert platform (bioMérieux, USA).

\section{Nucleic acid extraction}

Nucleic acids were extracted from $400 \mu \mathrm{L}$ of pleural fluid samples. An extraction and amplification control organism that is not associated with human pulmonary infections (Bacillus atrophaeus, Steris Life Sciences, USA) was added before extraction (20). Samples underwent bead beating using $0.5 \mathrm{~mm}$ beads (ZR BashingBeads, Zymo Research, USA) to break down bacterial cell walls using the Disruptor Genie device (Scientific Industries Inc, USA). Samples were then extracted and purified using an automated NA extraction device (iPrep, Life Technologies, USA), with a final volume of $50 \mu \mathrm{L}$. Extraction time was approximately $45 \mathrm{~min}$.

\section{Real-time polymerase chain reaction}

5 'exonuclease polymerase chain reaction (PCR) assays for the major bacterial CAP pathogens were used to test pleural fluid specimens. The PCR targets were the lytA gene for $S$ pneumoniae (21), the $h p d$ gene for $H$ influenzae (21), the nuc gene for $S$ aureus (22), the spy gene for $S$ pyogenes (23), and the $16 \mathrm{~S}$ ribosomal RNA gene of both Streptococcus intermedius and Streptococcus constellatus (two of the three species in the $S$ anginosus group) (24).

The limit of detection (LOD) for the assays was determined using serial dilutions of DNA extracted from reference strains of the organisms. The LOD was 100 organisms per PCR reaction for the $S$ pyogenes, $S$ aureus and $H$ influenzae assays; 10 organisms per PCR reaction for the $S$ pneumoniae assay; and one organism per PCR reaction for the $S$ intermedius/S constellatus assay (Table 1).

Uniplex PCR reaction assays for each target organism were prepared in $20 \mu \mathrm{L}$ volumes in 96-well PCR plates using an automated liquid handler (Eppendorf 5070, Eppendorf Canada, Canada). A negative control (no template) was performed with each sample. PCR plates were covered with adhesive film (MicroAmp Optical Adhesive Film, Life Technologies Inc, USA) to prevent cross-contamination. PCR was performed using a 96-well fast-cycling block on a ViiA7 thermocyler (Life Technologies Inc, USA) using 40 cycles of two-temperature thermocyling $\left(95^{\circ} \mathrm{C} \times 3 \mathrm{~s}\right.$ and $60^{\circ} \mathrm{C} \times 30 \mathrm{~s}$ ), taking approximately $40 \mathrm{~min}$ to complete.

\section{Statistical analysis}

Data were analyzed using STATA version 11.0 (Stata Corp, USA); 95\% CIs for proportions were calculated. Differences between PCR diagnostic results and traditional culture-based results were compared using the McNemar exact test.

\section{RESULTS}

A total of 56 pleural fluids were analyzed; the majority of patients had received antimicrobials before pleural fluid sampling. Molecular methods detected a pathogen in 46 of 56 samples, yielding an overall positivity rate of $82 \%$ (95\% CI $70 \%$ to $91 \%$ ). Pneumococcus was detected in 35 of 56 samples (62\% [95\% CI 49\% to $75 \%]$ ). The second most common causative pathogen was group A streptococcus, detected in nine of 56 samples (16\% [95\% CI $8 \%$ to $28 \%]$ ). Two of 56 samples (3.6\% [95\% CI $0.4 \%$ to $12 \%$ ) were positive using the $S$ intermedius/S constellatus assay. No pleural fluids were positive for $S$ aureus.

Cultures of blood and pleural fluids detected a pathogen in 14 of 56 patients (25\% [95\% CI $14 \%$ to $38 \%]$ ) - less than one-third the rate of detection using PCR; this difference was statistically significant $(\mathrm{P}<0.0001)$. Cultures were positive for $\mathrm{S}$ pneumoniae in eight of 56 patients 
TABLE 1

Real-time polymerase chain reaction $5^{\prime}$ exonuclease assays used for pleural fluid specimen testing

\begin{tabular}{|c|c|c|c|c|c|}
\hline \multirow[b]{2}{*}{ Organism } & \multirow{2}{*}{$\begin{array}{l}\text { Target } \\
\text { gene }\end{array}$} & \multicolumn{2}{|c|}{ Primer $\left(5^{\prime}-3^{\prime}\right)$} & \multirow[b]{2}{*}{ Probe } & \multirow[b]{2}{*}{ Ref } \\
\hline & & Forward & Reverse & & \\
\hline Streptococcus pneumoniae & lytA & ACGCAATCTAGCAGATGAAGCA & TCGTGCGTTTTAATTCCAGCT & AACGCTTGATACAGGGAG* & 21 \\
\hline Streptococcus pyogenes & spy & GCACTCGCTACTATTTCTTACCTCAA & GTCACAATGTCTTGGAAACCAGTAAT & $\begin{array}{l}\text { CCGCAACTCATCAAGGATT } \\
\text { TCTGTTACCA }^{\dagger}\end{array}$ & 23 \\
\hline Haemophilus influenzae & hpd & GGTTAAATATGCCGATGGTGTTG & TGCATCTTTACGCACGGTGTA & TTGTGTACACTCCGTTGGT* & 21 \\
\hline Staphylococcus aureus & nuc & AAATTACATAAAGAACCTGCGACA & GAATGTCATTGGTTGACCTTTGTA & $\begin{array}{l}\text { AATTTAACCGTATCACCAT } \\
\text { CAATCGCTTT }\end{array}$ & 22 \\
\hline
\end{tabular}

Streptococcus constellatus

Bacillus atrophaeus

atpD TTGTCTGTGAATCGGATCTTTCTC

CACTTCATTTAGGCGACGATACT

TCCCAATGTTACATTACC*

20

(positive control)

All assays were labelled with fluorescein amidite. *Probe modified from published with use of minor groove binder (MGB); †ZEN internal quencher (Integrated DNA

Technologies, USA) used; ${ }^{\ddagger}$ MGB probe used in place of dual fluorescence resonance energy transfer probes, forward and reverse primers lengthened at the 3 ' end to increase melting temperatures. Ref Reference; rRNA Ribosomal RNA

(14\% [95\% CI 6\% to 26\%]); this was significantly less sensitive than PCRbased detection $(\mathrm{P}<0.0001)$. Group A streptococcus was cultured from five of 56 patients (9\% [95\% CI 3\% to 20\%]); although almost twice as many samples were positive using PCR, this difference was not statistically significant $(\mathrm{P}=0.12)$. One of 56 cultures $(1.8 \%$ [95\% CI $0 \%$ to $10 \%])$ grew an organism identified as $\mathrm{S}$ constellatus. There were no other cultures of blood or pleural fluid positive for any other viridans group streptococci.

Every patient for whom an organism was grown in blood or pleural fluid had the same organism identified by pleural fluid PCR. Three pleural fluid samples had a positive Gram stain but were culturenegative. Two showed Gram-positive cocci in chains (one PCRpositive for group A streptococcus, one PCR-positive for $S$ pneumoniae) and one showed Gram-negative cocci. This latter sample was PCR positive for S pneumoniae. No pleural fluids or blood cultures were positive for $S$ aureus using culture or PCR.

\section{DISCUSSION}

In the present series, multiple-target uniplex real-time PCR of pleural fluids clearly outperformed traditional culture-based methods for the microbiological diagnosis of pneumonia with parapneumonic effusion. The benefit of molecular testing relative to culture was found to be greatest for the detection of $S$ pneumoniae, the most common cause of bacterial pneumonia in children.

Other investigators have also explored the use of PCR-based techniques for microbiological diagnosis of CAP complicated by parapneumonic effusion $(8,9,12,16-19)$. These studies were performed in different populations in different countries over different time periods with varying baseline pneumococcal vaccination rates. However, their results were consistent with ours in that $S$ pneumoniae was shown to be the most common pathogen causing parapneumonic effusion and that molecular detection of this pathogen was demonstrated to be more sensitive than traditional culture-based techniques.

One approach to the detection of multiple pathogens has been broad-range $16 \mathrm{~S}$ ribsomal RNA PCR. Pathogen detection in culturenegative cases has been shown to be $55 \%$ to $65 \%$ using this technique $(16,18)$, although a more recent study identified a pathogen in only $12 \%$ of children with negative blood and pleural fluid cultures (8). Using multiple-target uniplex real-time PCR, we identified a pathogen in 32 of $42(76 \%)$ culture-negative samples; these results are very similar to those of Blaschke et al (9), who used a nested PCR assay and identified bacteria in $73 \%$ of cases of culture-negative empyema. In contrast to that study, we did not detect any instances of polymicrobial infection. This discrepancy could be related to differential performance of the molecular assays under study. In other words, our assay may have had insufficient sensitivity or the assay used by Blaschke et al (9) (an 'open' nested assay) may have had suboptimal specificity. Our assay, being a 'closed' assay with multiple uniplex assays run simultaneously, would potentially be more easily adapted to a clinical laboratory setting using the appropriate automation.
Microbiological diagnosis has practical value in that it can facilitate the optimization of antimicrobial therapy. The Infectious Disease Society of America recommends that "empiric therapy with a 3rdgeneration parenteral cephalosporin should be prescribed...for infants and children with life-threatening infection, including those with empyema" (25). Our experience, and that of others (11), suggests that ceftriaxone and/or vancomycin are routinely prescribed for children admitted to Ontario hospitals with CAP-associated parapneumonic effusion and, because cultures are often negative, many children with complicated CAP receive broad-spectrum antimicrobial therapy for weeks. Prolonged use of advanced-generation cephalosporins and/or beta-lactam inhibitor combinations is, unfortunately, a concern. Widespread use of these agents has the potential to stimulate the accrual of resistant bacterial clones in the population at large (26).

The solution may be to improve diagnostics and thereby avoid both the under- and overtreatment risks inherent in empirical antimicrobial treatment algorithms. In our series, for example, had molecular testing been available in a timely manner, many patients (ie, those with group A streptococcus isolated from pleural fluids) may have been switched immediately to penicillin $G$ without fear of decreased efficacy. Furthermore, in our region, high-level penicillin resistance (minimum inhibitory concentration $\geq 8 \mu / \mathrm{mL}$ ) in $S$ pneumoniae is very rare, suggesting that penicillin $G$ or ampicillin could have been used successfully in most of our patients, consistent with Infectious Diseasees Society of America recommendations (25). Molecular methods to reliably determine penicillin susceptibility of pneumococci are not yet available; therefore, future studies should be performed to verify the safety of step-down therapy with ampicillin subsequent to the identification of $\mathrm{S}$ pneumoniae in populations in which rates of high-level penicillin resistance are low.

There were limitations to the present study. Given that our study population was a convenience sample of pleural fluids, we cannot make inferences about the relative frequency of respiratory pathogens causing pediatric complicated pneumonia in the greater population. We also did not collect data on the immunocompetence of the study participants nor their vaccination records. Regardless, it is interesting that group A streptococcus was the second-most common cause of complicated pneumonia and that we did not find $S$ aureus in any of our patients, despite the fact that participants were recruited during the $2009 \mathrm{pH} 1 \mathrm{~N} 1$ epidemic. It may be that our PCR assay may have had low sensitivity for S aureus; however, unlike $S$ pneumoniae, $S$ aureus can typically be grown in blood or pleural fluid cultures from the majority of children with empyema $(8,9,16,25,27)$; therefore, the fact that no cultures in the present study were positive for $\mathrm{S}$ aureus suggests that it was present very infrequently, if at all. We note that the LOD of our assays for S aureus was the same as it was for group A streptococcus, which we detected quite readily. A second potential limitation was that we used a PCR assay that detected $S$ intermedius and $S$ constellatus, but not $S$ anginosus, the third member of the $S$ anginosus group. We selected the assay used for the study based on the knowledge that 
S intermedius and S constellatus are significantly more commonly found in pleuropulmonary infections than $S$ anginosus (28); nevertheless, it is possible that our overall detection rate would have been higher if we had included a PCR assay targeting $S$ anginosus. The $S$ intermedius/S constellatus had the lowest LOD because this assay detects a multiple-copy target. Another potential limitation of our findings was that because the LODs for the PCR assays were not identical, organisms for which the LOD was lower may have been detected more readily than other organisms. However, the LOD for the $S$ pyogenes, $H$ influenzae and $S$ aureus assays were the same, and we detected $S$ pyogenes in several cases, suggesting the lack of detection of $\mathrm{H}$ influenzae and $\mathrm{S}$ aureus were not likely due to the sensitivity of the assays used for these organisms.

There are barriers to the widespread implementation of molecular testing for the detection of bacterial pathogens. These include concerns about the costs of such testing, the requirement to train laboratory staff to perform these tests and the need for dedicated space to perform testing. However, in clinical situations in which patients have been given antibiotics before specimen collection, such as described in our study of parapneumonic effusion, molecular detection of bacteria was clearly superior to culture-based methods.

\section{SUMMARY}

Retrospective use of molecular testing methods enabled us to dramatically increase microbiological diagnosis of CAP with parapneumonic

\section{REFERENCES}

1. Farha T, Thomson AH. The burden of pneumonia in children in the developed world. Paediatr Respir Rev 2005;6:76-82

2. Vuori-Holopainen E, Salo E, Saxen H, et al. Etiological diagnosis of childhood pneumonia by use of transthoracic needle aspiration and modern microbiological methods. Clin Infect Dis 2002;34:583-90.

3. Juven T, Mertsola J, Waris M, et al. Etiology of community-acquired pneumonia in 254 hospitalized children. Pediatr Infect Dis J 2000;19:293-8.

4. Kaplan SL, Mason EO Jr, Wald ER, et al. Decrease of invasive pneumococcal infections in children among 8 children's hospitals in the United States after the introduction of the 7-valent pneumococcal conjugate vaccine. Pediatrics 2004;113:443-9.

5. Li ST, Tancredi DJ. Empyema hospitalizations increased in us children despite pneumococcal conjugate vaccine. Pediatrics 2010;125:26-33.

6. Grijalva CG, Nuorti JP, Zhu Y, et al. Increasing incidence of empyema complicating childhood community-acquired pneumonia in the United States. Clin Infect Dis 2010;50: 805-13.

7. Finley C, Clifton J, Fitzgerald JM, et al. Empyema: An increasing concern in canada. Can Respir J 2008;15:85-9.

8. Gollomp K, Rankin SC, White C, et al. Broad-range bacterial polymerase chain reaction in the microbiologic diagnosis of complicated pneumonia. J Hosp Med 2011 October 12. DOI: $10.1002 / \mathrm{jhm} .911$ (Epub ahead of print)

9. Blaschke AJ, Heyrend C, Byington CL, et al. Molecular analysis improves pathogen identification and epidemiologic study of pediatric parapneumonic empyema. Pediatr Infect Dis J 2011;30:289-94.

10. Langley JM, Kellner JD, Solomon N, et al. Empyema associated with community-acquired pneumonia: A pediatric investigator's collaborative network on infections in Canada (PICNIC) study. BMC Infect Dis 2008;8:129.

11. Cohen E, Mahant S, Dell SD, et al. The long-term outcomes of pediatric pleural empyema: A prospective study. Arch Pediatr Adolesc Med 2012;166:999-1004.

12. Picazo J, Ruiz-Contreras J, Casado-Flores J, et al. Laboratory-based, 2-year surveillance of pediatric parapneumonic pneumococcal empyema following heptavalent pneumococcal conjugate vaccine universal vaccination in Madrid. Pediatr Infect Dis J 2011;30:471-4.

13. Martinon-Torres F, Dosil-Gallardo S, Perez del Molino-Bernal ML, et al. Pleural antigen assay in the diagnosis of pediatric pneumococcal empyema. J Crit Care 2012;27:321:e321-4.

14. Fredricks DN, Relman DA. Application of polymerase chain reaction to the diagnosis of infectious diseases. Clin Infect Dis 1999;29:475-86.

15. Dagan R, Shriker O, Hazan I, et al. Prospective study to determine clinical relevance of detection of pneumococcal DNA in sera of children by PCR. J Clin Microbiol 1998;36:669-73. effusion. If available prospectively in a timely manner, this information may enable physicians to select narrower-spectrum and less expensive antimicrobial therapies. We believe future prospective studies assessing the cost effectiveness of molecular assay-guided versus culture-guided management of CAP with parapneumonic effusion would be helpful. In areas where pneumococcal resistance to penicillin is prevalent, such studies could also integrate genotypic identification tests to better predict pneumococcal penicillin susceptibility in addition to pathogen detection (29).

FUNDING: This work was supported by Physicians' Services Incorporated Foundation Resident grant awarded in 2009.

ACKNOWLEDGEMENTS: JMP was instrumental in the conception and design of the study, performed the statistical analysis, and drafted the manuscript. IM and FC were instrumental in developing the techniques necessary to acquire data, revised the article, and approved its submission. RS was primarily responsible for conceiving the study question, supervised all microbiological testing and data acquisition, and provided important help in refining the manuscript before approving it for submission.

DISCLOSURES: The authors have no financial disclosures or conflicts of interest to declare.

16. Saglani S, Harris KA, Wallis C, et al. Empyema: The use of broad range 16s rDNA PCR for pathogen detection. Arch Dis Child 2005;90:70-3.

17. Obando I, Munoz-Almagro C, Arroyo LA, et al. Pediatric parapneumonic empyema, Spain. Emerg Infect Dis 2008;14:1390-7.

18. Le Monnier A, Carbonnelle E, Zahar JR, et al. Microbiological diagnosis of empyema in children: Comparative evaluations by culture, polymerase chain reaction, and pneumococcal antigen detection in pleural fluids. Clin Infect Dis 2006;42:1135-40.

19. Eastham KM, Freeman R, Kearns AM, et al. Clinical features, aetiology and outcome of empyema in children in the north east of england. Thorax 2004;59:522-5.

20. Picard FJ, Gagnon M, Bernier MR, et al. Internal control for nucleic acid testing based on the use of purified Bacillus atrophaeus subsp. Globigii spores. J Clin Microbiol 2009;47:751-7.

21. Wang X, Theodore MJ, Mair R, et al. Clinical validation of multiplex real-time PCR assays for detection of bacterial meningitis pathogens. J Clin Microbiol 2012;50:702-8.

22. Thomas LC, Gidding HF, Ginn AN, et al. Development of a realtime Staphylococcus aureus and MRSA (sam-) PCR for routine blood culture. J Microbiol Methods 2007;68:296-302.

23. Bacterial coinfections in lung tissue specimens from fatal cases of 2009 pandemic influenza a (h1n1) - United States, May - August 2009. MMWR Morb Mortal Wkly Rep 2009;58:1071-4.

24. Olson AB, Sibley CD, Schmidt L, et al. Development of real-time PCR assays for detection of the Streptococcus milleri group from cystic fibrosis clinical specimens by targeting the cpn60 and $16 \mathrm{~s}$ rRNA genes. J Clin Microbiol 2010;48:1150-60.

25. Bradley JS, Byington CL, Shah SS, et al. The management of community-acquired pneumonia in infants and children older than 3 months of age: Clinical practice guidelines by the Pediatric Infectious Diseases Society and the Infectious Diseases Society of America. Clin Infect Dis 2011;53:e25-76.

26. Conway PH, Cnaan A, Zaoutis T, et al. Recurrent urinary tract infections in children: Risk factors and association with prophylactic antimicrobials. JAMA 2007;298:179-86.

27. Strachan RE, Cornelius A, Gilbert GL, et al. Bacterial causes of empyema in children, Australia, 2007-2009. Emerg Infect Dis 2011;17:1839-45.

28. Claridge JE III, Attorri S, Musher DM, et al. Streptococcus intermedius, Streptococcus constellatus, and Streptococcus anginosus ("Streptococcus milleri group") are of different clinical importance and are not equally associated with abscess. Clin Infect Dis 2001;32:1511-5.

29. Chiba N, Morozumi M, Ubukata K. Application of the real-time PCR method for genotypic identification of beta-lactam resistance in isolates from invasive pneumococcal diseases. Microb Drug Resist 2012;18:149-56. 


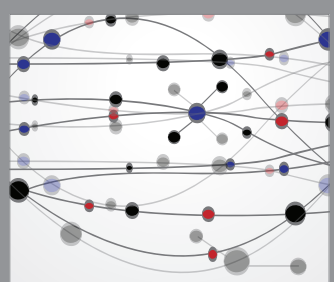

The Scientific World Journal
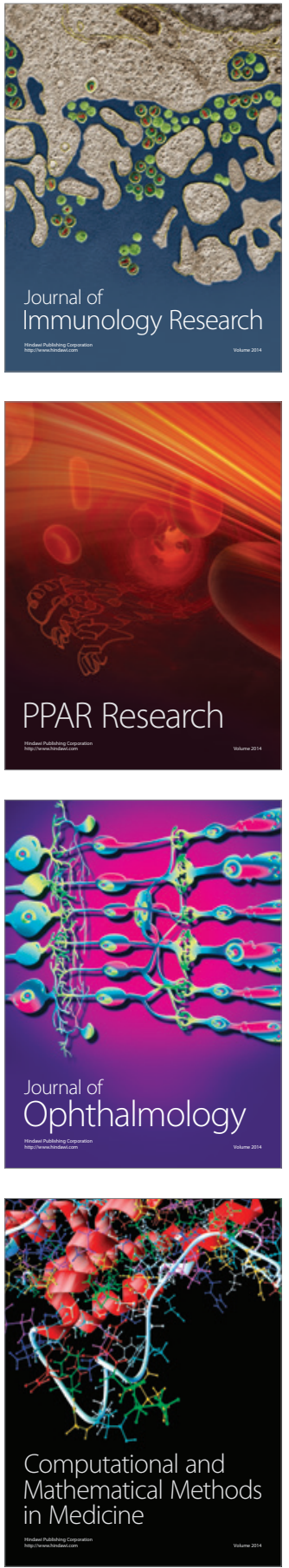

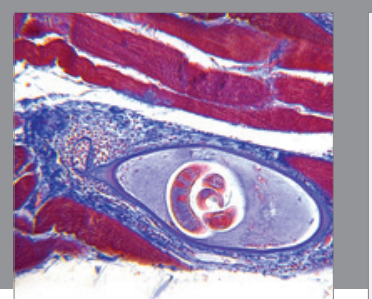

Gastroenterology Research and Practice

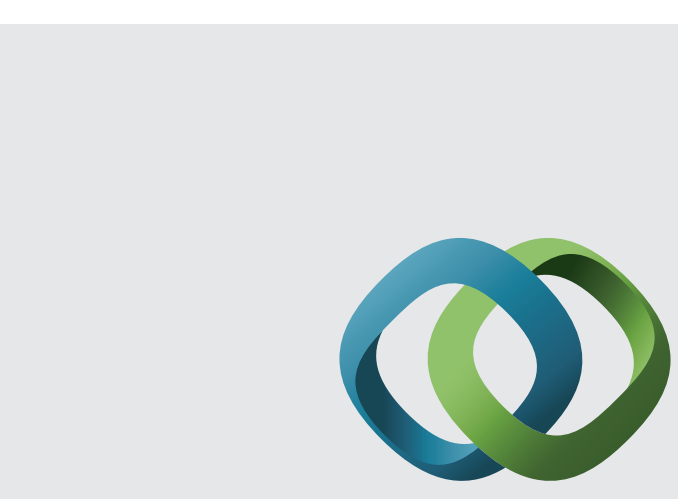

\section{Hindawi}

Submit your manuscripts at

http://www.hindawi.com
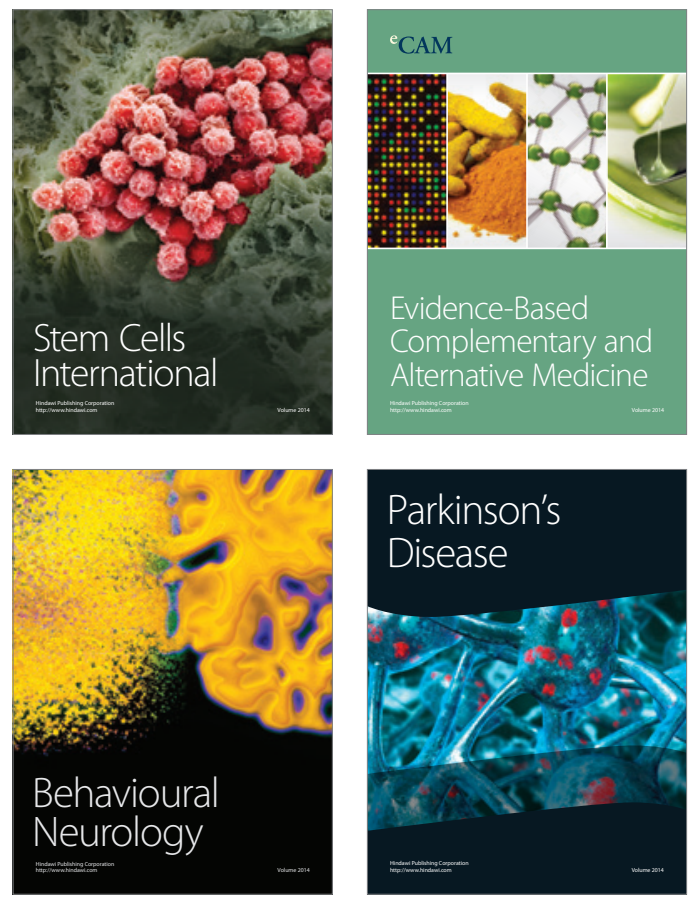
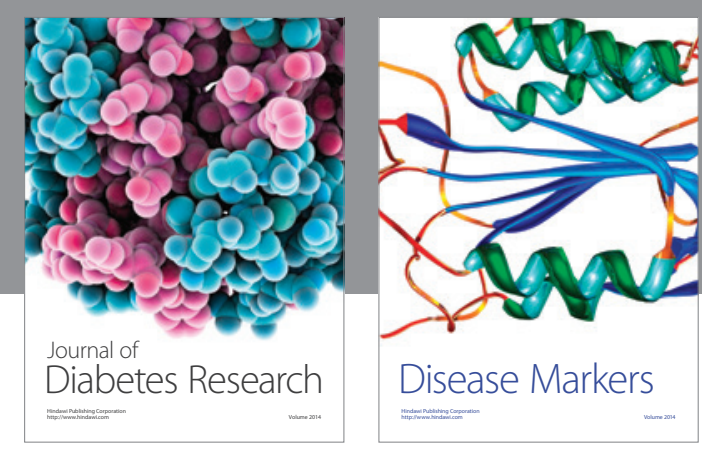

Disease Markers
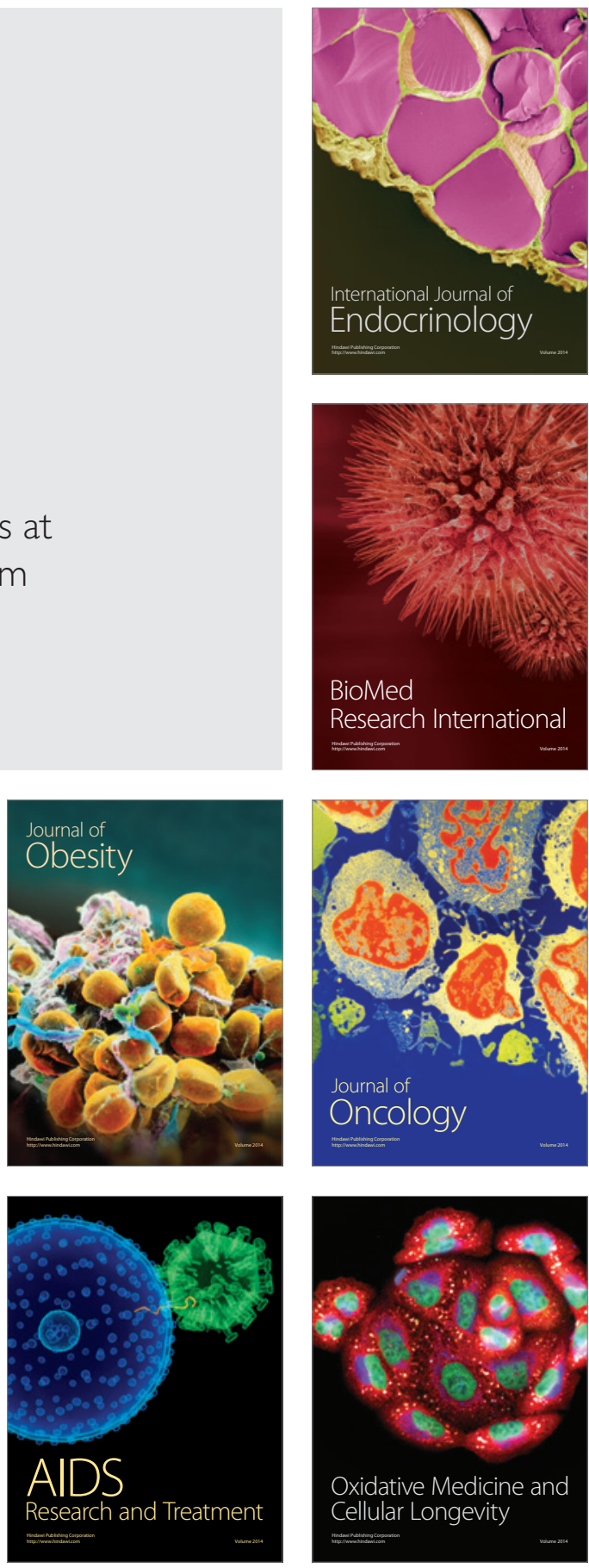